\title{
Investigating the Multi-Causal and Complex Nature of the Accident Causal Influence of Construction Project Features
}

DOI: $\underline{\text { https://doi.org/10.1016/j.aap.2011.05.008 }}$

Patrick A. Manu*, Nii A. Ankrah, David G. Proverbs and Subashini Suresh

School of Technology, University of Wolverhampton, Wolverhampton, WV1 1SB, UK.

\begin{abstract}
Construction project features (CPFs) are organisational, physical and operational attributes that characterise construction projects. Although previous studies have examined the accident causal influence of CPFs, the multi-causal attribute of this causal phenomenon still remain elusive and thus require further investigation. Aiming to shed light on this facet of the accident causal phenomenon of CPFs, this study examines relevant literature and crystallises the attained insight of the multi-causal attribute by a graphical model which is subsequently operationalised by a derived mathematical expression that offers a systematic approach for evaluating the health and safety impact of the accident causal influence of CPFs. The graphical model and the derived expression put forth by the study advance current understanding of the accident causal phenomenon of CPFs and present an opportunity for managing the health and safety impact of CPFs from the early stages of construction project procurement.
\end{abstract}

Keywords: accident, construction project features, health and safety, literature review, risk.

\section{Introduction}

An accident is any unplanned event that results in injury or ill-health of people, or damage or loss to property, plant, materials or the environment or a loss of a business opportunity (Hughes and Ferrett, 2008). Accidents are thus associated with adverse outcomes which have dire cost implications for the construction industry and society as a whole (cf. Darshi De Saram and Tang (2005), Imriyas et al. (2008), and Hughes and Ferrett (2008)). The adverse outcomes of accidents have created the need for accident prevention which requires knowledge of accident causal factors, how the causal factors contribute to accident causation, the extent to which causal factors contribute to accident causation, and the risk posed by these factors (Suraji et al., 2001; Hughes and Ferrett, 2008). The quest to acquire this knowledge has resulted in accident causation studies pioneered by Heinrich (1936). Beyond the unique contributions made by various accident causation studies to the understanding of accidents, they also generally demonstrate the complex and multi-causal nature of accidents (cf. Behm (2005), Elvik (2006), and Shapira and Lyachin (2009)) and as such the need to fully appreciate the complexity and multi-causality of any accident phenomenon in order to be able to adequately address accidents.

Construction project features (CPFs) are organisational, physical and operational characteristics of construction projects and until quite recently the accident causal phenomenon of these project characteristics has not been examined in greater depth despite their persistent mention in literature. In spite of the significant examination of the accident causal influence of CPFs (cf. Manu et al. (2010a)) the multi-causal attribute of this causal phenomenon still remain elusive and thus require further investigation. In an effort to shed light on this facet, this study begins with a review of some past accident

\footnotetext{
* Corresponding Author: Email: Patrick.Manu@wlv.ac.uk
} 
causation models to highlight the multi-causality of accidents and also to provide a sound theoretical underpinning for the study. The study proceeds to examine how CPFs contribute to accident causation to bring out the multi-causal dimension of the causal phenomenon of CPFs. Subsequently, the study presents an examination of the multicausal attribute in relation to the extent to which CPFs contribute to accident causation (i.e. their potential to cause harm) and the risk posed by CPFs. Through the examination, the study finally puts forth a derived mathematical expression which captures the multicausal attribute of the causal influence of CPFs and provides a systematic approach for assessing the health and safety $(\mathrm{H} \& \mathrm{~S})$ impact of CPFs.

\section{Accident causation models: A review}

Following the seminal work by Heinrich (1936) there have been considerable efforts toward investigating causes of accidents, how accidents occur and why they occur. These have resulted in several accident causation models, generally with the overall aim of providing tools for better industrial accident prevention. Accident causation models differ in many ways and may be classified based on their purpose, area of application, general structure, and key characteristics (Lehto and Salvendy, 1991; Chua and Goh, 2004). In reviewing accident causation models, three general categories are presented below i.e. energy transfer models, individual/human models and system/systematic models.

The energy transfer models view accident causation as the transmission of uncontrolled energy from a source through a path to the victim. An example is the energy transfer model by Haddon (1980). Haddon (1980) proposed 10 basic prevention strategies based on the points of intervention: the energy source, the path of energy transfer, and the victim. Despite its usefulness in categorizing types of preventive measures, Haddon's model has been criticized by Chua and Goh (2004) for not providing a suitable feedbackoriented framework for accident investigation and safety planning.

The individual/human specific models are models that place emphasis on the direct contribution made by individuals to accidents (Chua and Goh, 2004). These models identify the causes and effects of erroneous acts by individuals (usually front-line workers) and they usually focus on the psychological and behavioural aspects of humans (Chua and Goh, 2004). An example is the distraction theory by Hinze (1996). Human models thus do not explicitly facilitate the continual improvement of safety management systems as they do not emphasise the role of organisation and management in accident causation (Chua and Goh, 2004).

Systems/systematic models refer to models that highlight the role of the organization and its systems in the causation of accident (Chua and Goh, 2004). The models view accidents as by-products of a production system and they focus on the characteristics of the production system that generate hazardous situations and shape the behaviour of workers (Mitropoulos et al., 2005). Systemic models also view accidents as emergent phenomena, which arise due to the complex interactions between system components (human, technical, organisational and management) that may result in an accident (Qureshi, 2007). Henderson et al. (2001) regarded a system-based approach to accident causation as one of the requirements of a successful accident investigation. Mitropoulos et al. (2005) also argued that effective causation models need to take a systems view of safety and provide better understanding of how the characteristics of a production system generate unsafe conditions and shape the behaviour of workers. Examples of systems models are the pathogen model (Reason, 1990), the loss causation model (Bird and Germain, 1996), the modified loss causation model (Chua and Goh, 2004), the constraintresponse model (Suraji et al., 2001), and the ConCA model (Loughborough University and UMIST, 2003). These models are concerned with the underlying mechanisms of 
accident causation (which are generally latent/subtle), the induced/generated immediate causes and the complex interactions between them. These models thus reinforce the multi-causality of accidents.

From the above broad classifications of accident causation models, the accident causal phenomenon of CPFs can be viewed from the perspective of systematic causation models as CPFs in their contribution to accident causation function as underlying (latent/subtle) determinants of the nature, extent and existence of immediate causes of accidents (cf. Haslam et al. (2005)). The alignment of the causal phenomenon of CPFs with the systems view of accident causation is further reinforced by the following detailed examination of the process by which CPFs contribute to accident causation which points out the complex and multi-causal attribute of the causal phenomenon of CPFs.

\section{How CPFs contribute to accident causation}

Manu et al. (2010a) through an extensive review of the construction $H \& S$ literature reported the accident causal influence of construction project features such as the nature of project, method of construction, site restriction, project duration, procurement system, design complexity, level of construction, and subcontracting. These CPFs are organisational, operational, and physical attributes that characterise construction projects and like other originating influences in construction accidents, these CPFs are high level determinates of the nature, extent and existence of immediate causes of accidents (Haslam et al., 2005). A succinct representation of the review presented by Manu et al. (2010a) is shown in Table 1 which clearly indicates that the accident causal influence of CPFs is undeniably existent and has persistently been reported albeit in a somewhat disparate and fragmented manner.

Table 1: Summary of literature highlighting the accident causal influence of CPFs

\begin{tabular}{|c|c|c|c|c|c|c|c|c|c|c|c|c|c|c|c|c|c|}
\hline $\begin{array}{l}\text { Literature } \\
\text { Sources }\end{array}$ & 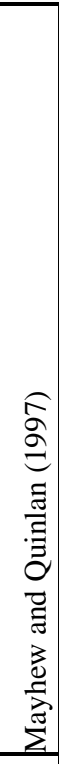 & 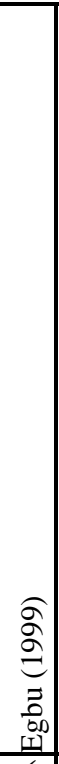 & 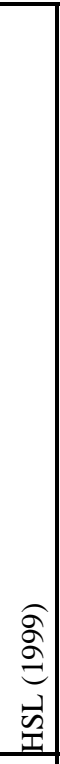 & 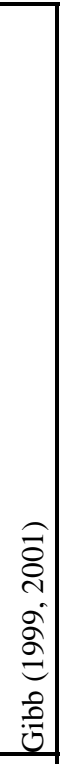 & 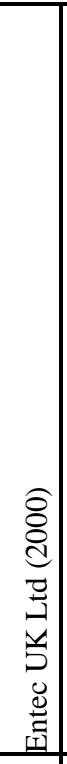 & 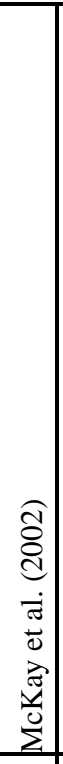 & 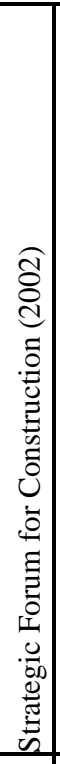 & 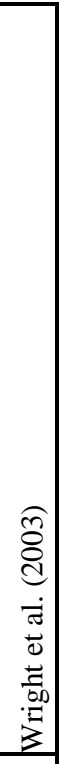 & 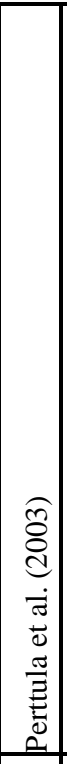 & 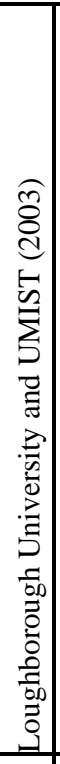 & 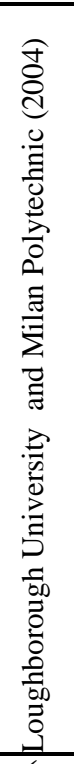 & 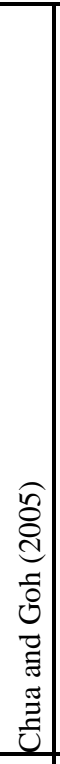 & 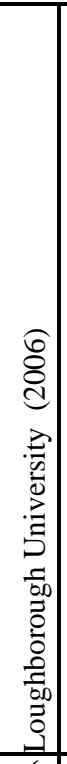 & 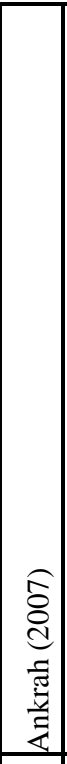 & 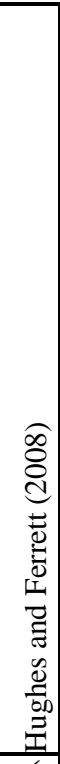 & 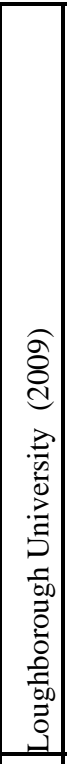 & 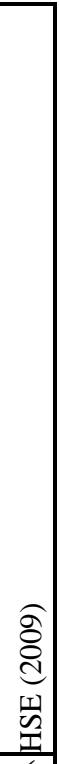 \\
\hline Nature of Project & & $\checkmark$ & & & & & & & & & $\checkmark$ & & $\checkmark$ & & $\checkmark$ & & $\checkmark$ \\
\hline Method of Construction & & & & $\checkmark$ & & $\checkmark$ & $\checkmark$ & $\checkmark$ & $\checkmark$ & $\checkmark$ & & & & & & & \\
\hline Site Restriction & & & & & $\checkmark$ & & & & & $\checkmark$ & & & & & & $\checkmark$ & \\
\hline Project Duration & $\checkmark$ & & & & $\checkmark$ & & & & & $\checkmark$ & & & & & & $\checkmark$ & \\
\hline Procurement System & & & $\checkmark$ & & $\checkmark$ & & & & & $\checkmark$ & & & & & & & \\
\hline Design Complexity & & & & & $\checkmark$ & & & & & $\checkmark$ & & & & & & $\checkmark$ & \\
\hline Level of Construction & & & & & & & & & & & & $\checkmark$ & & & $\checkmark$ & & $\checkmark$ \\
\hline Subcontracting & $\checkmark$ & & $\checkmark$ & & & & & & & $\checkmark$ & & & & $\checkmark$ & & $\checkmark$ & \\
\hline
\end{tabular}


CPFs emanate to a large extent from the client's brief, design decisions and project management decisions at the pre-construction stage of project procurement (cf. Suraji et al. (2001), Cheng et al. (2005) and Haslam et al. (2005)) and they contribute to the causation of accidents through the introduction of other accident causal factors into the construction stage. These other causal factors which give rise to accidents are termed proximal causal factors (PFs) (Suraji et al., 2001; Haslam et al., 2005). Proximal factors are closer to accident events than CPFs which are distal to accident events and are therefore also termed distal/root/originating causal factors (Suraji et al., 2001; Haslam et al., 2005). This basic understanding of how CPFs contribute to accident causation is illustrated in Figure 1. A summary of the proximal factors that are introduced by CPFs as initially discussed by Manu et al. (2010a) is also presented in Table 2.

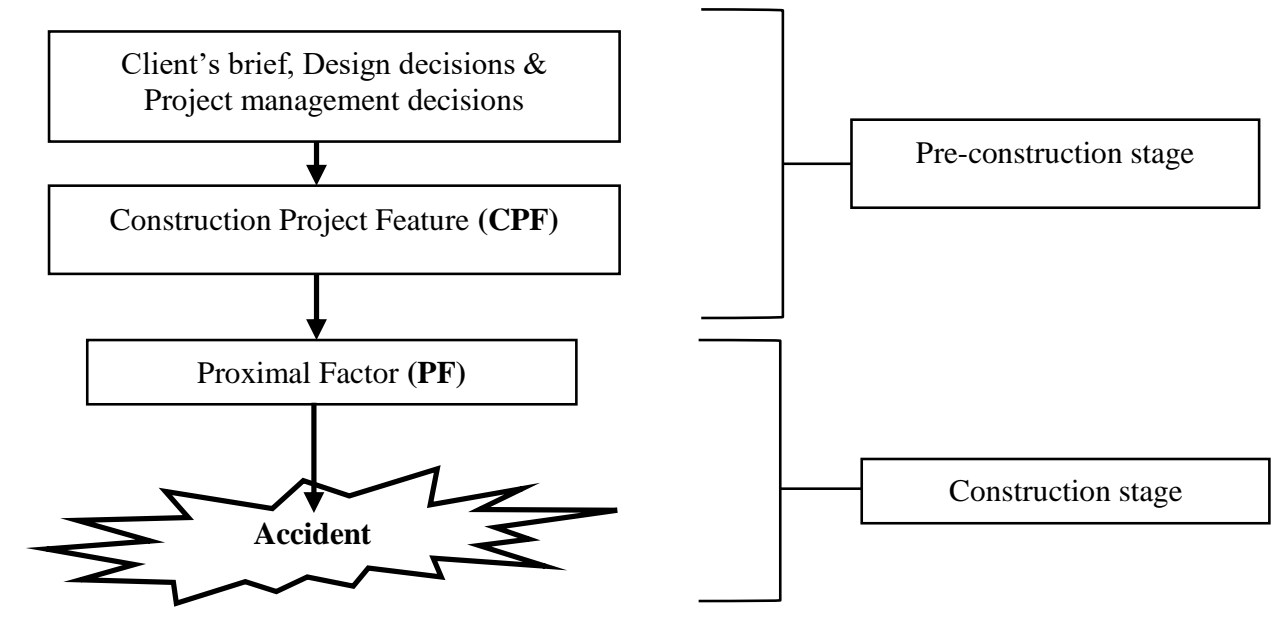

Figure 1: Pattern of contribution of CPFs to accident causation (Adapted from Suraji et al. (2001), Haslam et al. (2005) and Reason (1990))

Table 2: Summary of CPFs and Proximal Factors

\begin{tabular}{|c|c|}
\hline CPFs & Proximal Factors \\
\hline Nature of project & $\begin{array}{l}\text { Uncertainty \& complexity of hazards (Egbu, 1999; Loughborough University, } \\
\text { 2006) }\end{array}$ \\
\hline $\begin{array}{l}\text { Method of } \\
\text { Construction }\end{array}$ & Manual handling (McKay et al., 2002; Wright et al., 2003) \\
\hline Site Restriction & $\begin{array}{l}\text { Site congestion (Loughborough University and UMIST, 2003; Loughborough } \\
\text { University, 2009) }\end{array}$ \\
\hline Project Duration & $\begin{array}{l}\text { Time-pressure (Loughborough University and UMIST, 2003; Loughborough } \\
\text { University, 2009) }\end{array}$ \\
\hline Procurement System & $\begin{array}{l}\text { Fragmentation of project team (HSL, 1999; Entec UK Ltd, 2000; Loughborough } \\
\text { University and UMIST, 2003) }\end{array}$ \\
\hline Design Complexity & $\begin{array}{l}\text { Difficulty in constructing (Loughborough University and UMIST, 2003; } \\
\text { Loughborough University, 2009) }\end{array}$ \\
\hline Level of Construction & Working at height/confined space (Hughes and Ferrett, 2008; HSE, 2009) \\
\hline Subcontracting & $\begin{array}{l}\text { Fragmentation of workforce (Mayhew and Quinlan, 1997; Loughborough } \\
\text { University and UMIST, 2003; Ankrah, 2007) }\end{array}$ \\
\hline
\end{tabular}


As established in literature, accidents are multi-causal (Loughborough University and UMIST, 2003; Behm, 2005) which therefore means that considering the accident causal phenomenon of CPFs, there could be several CPFs contributing to the causation of an accident(s). Again, referring to the accident causal phenomenon of CPFs, the multicausal nature of accidents also manifests itself through complex causal interactions that transpire between CPFs and the proximal factors they introduce in the causation process and this reflects the systems view of accident causation. For instance it is established knowledge that a particular method of construction (i.e. pre-assembly) can reduce site congestion (i.e. a proximal factor) which could be introduced by the physical restriction of a site (Wright et al., 2003).

Another dimension of the multi-causal nature of the causal influence of CPFs is the possible introduction of multiple proximal factors by a CPF. For instance, apart from the introduction of manual handling by method of construction, method of construction could also introduce housekeeping problems (cf. Wright et. al. (2003)) which Loughborough University and UMIST (2003) identified to contribute to accidents. Evidently this dimension further complicates the complexity surrounding the causal phenomenon of CPFs and it would be useful to have a model that tries to capture this complexity. As in several accident causation studies, graphical models have been used to advance the understanding of the complexity and multi-causality of accident causation (cf. Suraji et. al. (2001), Mitropoulos et al. (2005), and Haslam et al. (2005)), and in the context of the causal phenomenon of CPFs, Figure 2 can similarly be put forth in the light of the above discussion.

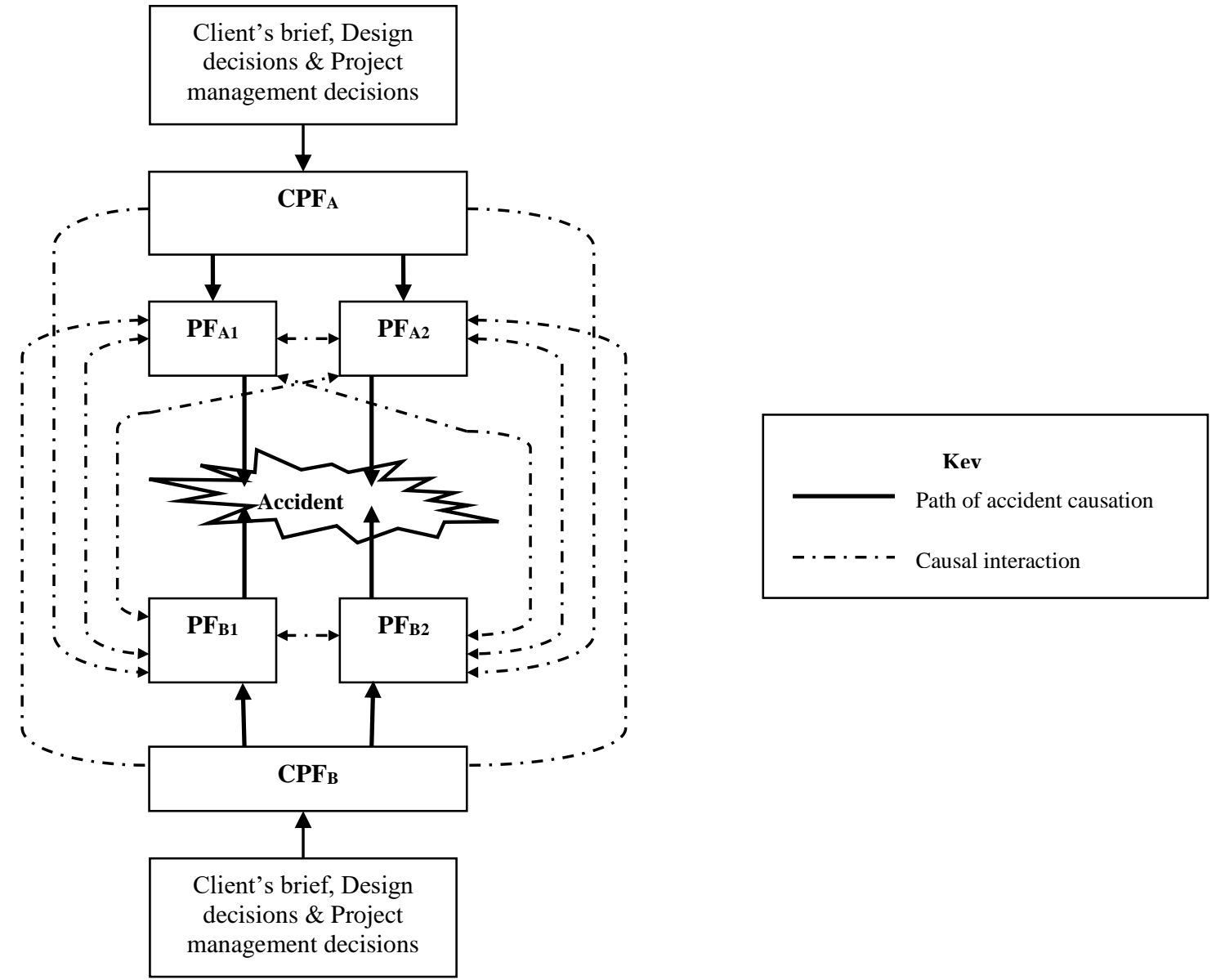

Figure 2: The multi-causal influence of CPFs 
Beyond illustrating the basic path of causation (i.e. from underlying factors through proximal factors to accidents), Figure 2 adds to current understanding of the accident causal phenomenon of CPFs by its enhanced depiction of the multi-causal nature of this phenomenon. From it's depiction of underlying and proximal causal influences and the causal interactions between them, Figure 2 clearly shows that the accident causal phenomenon of CPFs reflects the systems/systematic view of accident causation. Drawing on Figure 2, the following sections now examine the multi-causal attribute of the causal influence of CPFs in relation to the extent to which CPFs contribute to accident causation and the H\&S risk posed by CPFs.

\section{The extent of contribution of CPFs to accident causation}

Concerning the extent to which CPFs contribute to accident causation, the review by Manu et al. (2010b) demonstrates that it varies depending on the degree of prevalence of proximal factors within their associated CPFs. This implies that the more common/prevalent a proximal factor is within a CPF the greater the extent to which the CPF contributes to accident causation as shown by the continuum in Table 3 .

It can however be also argued that the extent to which CPFs contribute to accident causation is primarily influenced by the extent to which their related proximal factors contribute to accident causation (Manu et al., 2010b). This is because it is by reason of the related proximal factors contributing to the causation of accidents in the first place that the CPFs are also able to contribute to accident causation as a result of their introduction of the proximal factors. This means that if a proximal factor does not contribute to accident causation, no matter its prevalence within a CPF that CPF will not also contribute to accident causation (Manu et al., 2010b). Advancing this argument further, the extent to which a CPF contributes to accident causation is therefore the combined effect of;

- the extent to which the related proximal factor contributes to accident causation (represented by ' $\mathrm{R}$ ') ; and

- the extent to which the proximal factor is prevalent/common within the CPF (represented by 'r') (Manu et al., 2010b).

From Table 3 it can be seen that whereas factor ' $r$ ' alone provides the opportunity for relative comparison among $\mathrm{CPF}$ of the same kind (e.g. partnering and management contracting), in terms of their extent of contribution to accident causation, the combined effect of ' $r$ ' and ' $R$ ' would enable the relative comparison among CPFs of different kinds (e.g. conventional construction and management contracting) as the combined effect takes into account the direness of proximal factors (i.e. ' $R$ '). The combined influence of ' $r$ ' and ' $R$ ' is therefore a holistic and better depiction of the extent to which CPFs contribute to accident causation (Manu et al., 2010b). The extent to which CPFs contribute to accident causation indicates the extent to which they contribute to harm and hence an indication of their potential to cause harm. This is a useful insight for accident prevention as it provides the opportunity for identifying CPFs that have a relatively high potential to cause harm. To enable a quantitative assessment of the extent to which CPFs contribute to accident causation, Manu et al. (2010b) presented a mathematical expression showing that the extent to which a CPF contributes to accident causation (represented by ' $C$ ') is a function of ' $R$ ' and ' $r$ ' (i.e. $\mathbf{C}=f(\mathbf{R}, \mathbf{r})$ ). By adapting the method of mathematical combination by multiplication as used in mathematical risk expressions (e.g. Risk = hazard x exposure (CCHOS, 2008)), Manu et al. (2010b) put forth the expression, $C=R x r$, i.e. ' $\mathrm{C}$ ' is the combined effect/influence of ' $\mathrm{R}$ ' and ' $\mathrm{r}$ ' where ' $R$ ' and ' $r$ ' are qualitative-quantitative ratings as commonly used in quantitative 
risk assessment (cf. Hughes and Ferrett (2008)). In spite of the utility of this expression in enabling comparative assessment of the potential of CPFs to cause harm, its limitation is evident in the fact that it does not capture the multi-causal nature of the causal influence of CPFs, especially where a CPF introduces multiple proximal factors.

Table 3: Extent of contribution of CPFs to accident causation

\begin{tabular}{|c|c|}
\hline Proximal Factors & $\begin{array}{l}\text { Extent of Contribution of CPF to Accident Causation } \\
\text { (Prevalence of proximal factor within CPF) }\end{array}$ \\
\hline $\begin{array}{l}\text { Uncertainty and complexity } \\
\text { of hazards (Egbu, 1999; } \\
\text { Loughborough University, } \\
\text { 2006) }\end{array}$ & $\begin{array}{l}\text { Refurbishment } \\
\text { Demolition }\end{array}$ \\
\hline $\begin{array}{l}\text { Manual handling (McKay et } \\
\text { al., 2002; Wright et al., } \\
\text { 2003) }\end{array}$ & Conventional on-site construction \\
\hline $\begin{array}{l}\text { Site congestion } \\
\text { (Loughborough University } \\
\text { and UMIST, 2003; } \\
\text { Loughborough University, } \\
\text { 2009) }\end{array}$ & Unrestricted site \\
\hline $\begin{array}{l}\text { Time pressure } \\
\text { (Loughborough University } \\
\text { and UMIST, 2003; } \\
\text { Loughborough University, } \\
\text { 2009) }\end{array}$ & Unconstrained duration \\
\hline $\begin{array}{l}\text { Fragmentation of project } \\
\text { team (HSL, 1999; Matthews } \\
\text { and Rowlinson, 1999; Entec } \\
\text { UK Ltd, 2000; } \\
\text { Loughborough University } \\
\text { and UMIST, 2003; Baiden et } \\
\text { al., 2006; Eriksson, 2010) }\end{array}$ & Traditional procurement \\
\hline $\begin{array}{l}\text { Difficulty in constructing } \\
\text { (Loughborough University } \\
\text { and UMIST, 2003; } \\
\text { Loughborough University, } \\
\text { 2009) }\end{array}$ & $\begin{array}{l}\text { Simple Design } \\
\text { (Simple aesthetic qualities) }\end{array}$ \\
\hline $\begin{array}{l}\text { Working at height / Confined } \\
\text { space (Hughes and Ferrett, } \\
\text { 2008; HSE, 2009) }\end{array}$ & $\begin{array}{l}\text { Multi/High-level construction } \\
\text { Underground construction }\end{array}$ \\
\hline $\begin{array}{l}\text { Fragmentation of work force } \\
\text { (Mayhew and Quinlan, 1997; } \\
\text { Loughborough University } \\
\text { and UMIST, 2003; Ankrah, } \\
\text { 2007) }\end{array}$ & Single-layer subcontracting \\
\hline
\end{tabular}

In light of the multi-causal nature of the causal influence of CPFs, it is therefore appropriate to modify the expression as follows: $\mathrm{C}=f\left(\mathrm{R}_{1}, \mathrm{r}_{1} ; \mathrm{R}_{2}, \mathrm{r}_{2} ; \ldots ; \mathrm{R}_{\mathrm{n}}, \mathrm{r}_{\mathrm{n}}\right)$, where ' $\mathrm{n}$ ' is the number of proximal factors that may be introduced by a CPF. The independent contribution by the ' $\mathrm{n}$ ' proximal factors using the method of combination (i.e. multiplication) would thus be; $C_{1}=r_{1} \times R_{1} ; C_{2}=r_{2} \times R_{2} ; \ldots ; C_{n}=r_{n} \times R_{n}$. Evidently, the challenge posed by this scenario in contrast to where a CPF introduces a single proximal 
factor is the amalgamation of the individual effects (i.e. $C_{1}, C_{2}, \ldots, C_{n}$ ). Given that, the proximal factors are each contributing to the causation of accident through their introduction by a $\mathrm{CPF}$, the scenario can be conceptualised in structural engineering terms as a system of forces where $\mathrm{C}_{1}, \mathrm{C}_{2}, \ldots, \mathrm{C}_{\mathrm{n}}$ are the individual forces making up a resultant force (i.e. C) as shown in Figure 3. The use of structural engineering concept in health and safety research is not far fetched. Hallowell and Gambatese (2009) similarly adapted a structural engineering concept (i.e. the structural capacity of a beam) when conceptualising the risk capacity of a site safety programme.

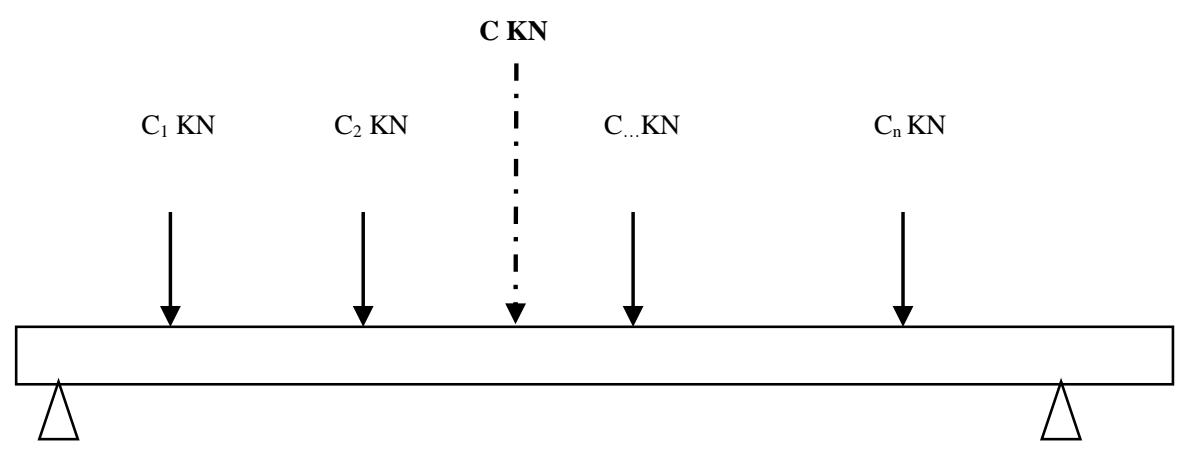

Figure 3: A system of forces

As shown in Figure 3, the resultant of the individual forces (i.e. C) will thus be;

$\mathrm{C}=C_{1}+C_{2}+\ldots+C_{n}$. Relating this to the introduction of multiple proximal causal factors by a $\mathrm{CPF}$, the extent of contribution of a $\mathrm{CPF}$ to accident causation $(\mathrm{C})$ can be expressed as;

$\mathrm{C}=C_{1}+C_{2}+\ldots+C_{n .}=r_{1} \times R_{1}+r_{2} \times R_{2}+\ldots+r_{n} \times R_{n}$.

Relating the causal interactions that transpire between CPFs and proximal factors to the extent to which CPFs contribute to accident, literature indicates that the causal interactions affect the degree of prevalence of proximal factors within CPFs (i.e. ' $r$ '). For example where pre-assembly construction is present with high rise construction, a restricted site and/or constrained project duration, the pre-assembly construction can reduce the extent (i.e. prevalence) of working at height, site congestion and time pressure that would be introduced by the high level construction, the restricted site and the constrained project duration, respectively (Wright et al., 2003). Conversely where conventional on-site construction is used on a restricted site, there could be an aggravation of the site congestion introduced by the restriction of the site. It can be further argued that the decreasing-increasing (mitigating-aggravating) effect of the causal interaction on ' $r$ ' is not static but rather dynamic given the dynamic nature of construction (Hallowell and Gambatese, 2009). An example is the dynamic effect which conventional construction could have on the extent of congestion given that conventional construction involves on-site production and is labour intensive. This means that at certain periods (depending on the construction programme) there may be fewer/greater piles of materials on site and also fewer/more operatives on site which would increase or decrease the extent of congestion imposed by the restriction of the construction site. This dynamism clearly reflects the complexity of accident causation which Groeneweg (1994) likened to a marble standing on a rough plateau of which the undermining mechanism likely to cause its moving and dropping is unpredictable. This dynamism also imposes challenges in the assessment of the potential of CPFs to cause harm especially from the perspective of the pre-construction stage of project procurement where minute details of on-site construction operations are less likely to be known. Nonetheless, the above 
expression provides the opportunity for a systematic independent assessment of the potential of CPFs to cause harm which can be complemented by the knowledge of potential causal interactions between CPFs and proximal factors. Given that the preconstruction phase offers the greatest opportunity for influencing the H\&S outcomes of projects (Szymberski, 1997) and CPFs emanate from this stage, these two strands of information could be useful to project participants at the pre-construction stage in devising measures for mitigating the accident causal influence of CPFs. Having examined the multi-causality of the accident causal phenomenon of CPFs in the light of the potential of CPFs to cause harm, the subsequent section of the study examines its implication for the health and safety risk posed by CPFs.

\section{The health and safety risk posed by CPFs}

Concerning the $\mathrm{H} \& \mathrm{~S}$ risk associated with $\mathrm{CPFs}$, the insight provided by $\mathrm{H} \& \mathrm{~S}$ literature is simplistic and limited to a few CPFs. For instance refurbishment has been associated with a higher risk than new work (cf. Loughborough University (2006)), and conventional construction has also been associated with a higher risk than pre-assembly construction (cf. McKay et al. (2002)). This limitation in the literature therefore implies the need to evaluate the risk posed by CPFs as it is inadequate to use the extent to which CPFs contribute to accident causation (i.e. potential to cause harm) as the sole basis for accident prevention. Though simplistic, these risk evaluations reflect the illustration in Table 3 where refurbishment and conventional construction have a higher potential to cause harm than new work and pre-assembly construction respectively.

Regarding this link between the extent of contribution of CPFs to accident causation and H\&S risk, the risk expressions put forth by Chicken and Posner (1998) and the Canadian Centre for Occupational Health and Safety (CCOHS) (2008) provide some illumination. Chicken and Posner (1998) and the CCOHS (2008) indicate that risk is a function of hazard and exposure, expressed as Risk = Hazard x Exposure. Duffus and Worth (2001) also argued that risk is a function of hazard and exposure because, no matter the severity of a hazard if there is no exposure, there would be no risk of harm. Hazard is the potential of a source or substance to cause harm and risk is the likelihood of a source or substance to cause harm (Hughes and Ferrett, 2008). Exposure is the extent to which people are subjected to the hazard (CCOHS, 2008) and can be assessed in terms of duration (Duffus and Worth, 2001; CCOHS, 2008). Given that the extent to which CPFs contribute to accident causation indicates their potential to cause H\&S harm, the above risk expression is useful in providing understanding into the relationship between the extent of contribution of CPFs to accident causation (i.e. their potential to cause H\&S harm) and $\mathrm{H} \& \mathrm{~S}$ risk (i.e. their likelihood to cause $\mathrm{H} \& \mathrm{~S}$ harm).

The risk expression (i.e. Risk $=$ Hazard $\mathrm{x}$ Exposure) can thus be adapted for the context of the accident causal influence of CPFs as, Risk (Rk) = Potential of a CPF to cause harm (C) $x$ Exposure $(E)$, where exposure is assessed in terms of the duration within which the workforce is subjected to the CPFs. Drawing on the above expression, $\mathrm{C}=C_{1}+C_{2}+\ldots+$ $C_{n}$, the health and safety risk associated with a CPF can thus be generally written as;

$R k=C x E=\left(C_{1}+C_{2}+\ldots+C_{n}\right) x E=\left(r_{1} x R_{1}+r_{2} x R_{2}+\ldots+r_{n} x R_{n .}\right) x E$.

By this expression, the H\&S risk associated with a CPF is thus the combined effect of;

- the extent to which the related proximal factors contribute to accident causation (i.e. the potential of the proximal factors to cause harm, represented by 'R') ;

- the extent to which the proximal factors are prevalent/common within the CPF (represented by ' $r$ '); and the 
- duration of exposure of the construction workforce to the CPF (represented by "E”).

For simplicity of measurement, rather than measuring duration of exposure in terms of actual time units (e.g. days, weeks) an 'exposure index' can be used. This exposure index can be assessed relative to the project duration similar to the assessment of relative density (i.e. ratio of the density of a substance to the density of water (Abbott, 1984)) as commonly used in the physical sciences and in engineering. Using this exposure index would also facilitate the comparative assessment of the risk posed by CPFs. To illustrate, the exposure index of subcontracting for a project would be, $d_{s} / D$; where ' $d_{s}$ ' is the anticipated duration of subcontracting, and ' $D$ ' is the anticipated project duration. Obviously for some CPFs such as a restricted site, the duration of exposure will be the same as the anticipated project duration. The above risk expression reflects a key element of the accident causal influence of CPFs (which is the multi-causal nature) and the study now examines the utility of the expression for accident prevention and also its implication for further research.

\section{Implications for accident prevention and research}

As previously mentioned, CPFs emanate to a large extent from decisions by the client, design team and project management team at the pre-construction stage which offers project participants the greatest scope to influence the H\&S outcomes of project (Szymberski, 1997; Entec UK Ltd., 2000). The above risk expression, being a mechanism for the systematic comparative analysis of the H\&S risk associated with CPFs, it provides pre-construction decision-makers (the client, project management team, and decision team) the opportunity to make decisions that will promote positive on-site H\&S on the basis of the systematic assessment of H\&S risk posed by CPFs. However, at present, there are no quantitative measures for the determinant factors of the extent to which CPFs contribute to accident causation (i.e. "R" and " $r$ ") and this offers an opportunity for further studies to determine these inputs for subsequent application in the derived $H \& S$ risk expression. The attainment of these inputs would further entrench the utility of the risk expression as pre-construction decision-makers would be able to systematically evaluate the potential of CPFs to cause harm and consequently the H\&S risk implications and on that basis possibly select CPFs that have low potential to cause harm and/or a low risk. However, in practice, these project participants are faced with certain constraints which also influence their decisions (Suraji et al., 2001), and this means that the client, design team and project management team may be constrained by certain factors to choose CPFs which may have significant adverse impact on H\&S. For instance where the client requires a facility to be completed within a constrained duration (probably as a result of a business plan), or where the site available for the development is a highly restricted site, or where the client requires a multi-level facility, these would impose constraints on the design team and project management team to go by such CPFs despite their potentially adverse H\&S effects. Where such CPFs are inevitable, or as it were 'fixed', depending on constraints faced by pre-construction decision-makers, other risk mitigation measures (e.g. measures to eliminate or reduce the prevalence of proximal factors) could be introduced by the decision-makers (through some aspects of the project design and management), and also by the construction team when preparing the construction phase plan. The knowledge of the causal interactions between CPFs and proximal factors as depicted by the graphical model could especially be useful in selecting CPFs that could potentially reduce the prevalence of proximal factors or possibly avoiding CPFs that could aggravate the prevalence of the proximal factors that are introduced by other CPFs. Beyond the known mitigating/aggravating interaction effects offered by method of construction, it is important to investigate other potential interactions between CPFs and proximal factors, and this also presents another 
opportunity for research. Given that the pre-construction stage offers project participants the greatest opportunity to influence the H\&S outcomes of projects, it is anticipated that the graphical model and the derived mathematical risk expression (both of which reflect the complex and multi-causal attribute of the causal phenomenon of CPFs) would be useful to pre-construction decision-makers and also to the construction team in managing the H\&S impact associated with CPFs.

\section{Conclusions}

By examining H\&S literature, this study has shed light on the multi-causal attribute of the accident causal influence of CPFs in greater depth and by that has advanced the understanding of this causal phenomenon. The study has achieved this by revealing the process by which CPFs contribute to accident causation pointing out the path of causation (from CPFs (i.e. underlying causal influences) through proximal factors to accidents), the possible introduction of multiple proximal factors by CPFs, and the dynamism of the complex causal interactions between $\mathrm{CPFs}$ and proximal factors. The study has thus shown that the causal phenomenon of CPFs reflects the systems view of accident causation, and the study has captured this complex and multi-causal attribute of the causal phenomenon of CPFs by a graphical model. The model has been operationalised by a derived mathematical expression that offers a systematic approach for evaluating the $\mathrm{H} \& \mathrm{~S}$ impact of CPFs. The graphical model and the mathematical expression are thus useful tools for accident prevention. However their present utility is limited as the quantitative inputs to be applied in the expression as well as the insight of other potential causal interactions which is needed to complement the utility of the model and expression are presently unknown. These unknowns thus pose a challenge to the utility of the expression and the model and as such must be obtained by research if the benefits of the model and the expression are to be entrenched. On-going research which aims to provide these unknowns offers some hope and it is anticipated that the final outcome of the research will help improve $H \& S$ on construction projects through the systematic analysis of $\mathrm{H} \& \mathrm{~S}$ impact of CPFs for subsequent application in pre-construction decisionmaking/planning and accident prevention.

\section{References}

Ankrah, N. A. (2007) An investigation into the impact of culture on construction project performance. PhD theis, School of Engineering and the Built Environment, University of Wolverhampton.

Abbott, A. F. (1984) Ordinary level physics, $4^{\text {th }}$ Edition, London: Heinemann Educational Books.

Baiden, B. K., Price, A. D. F., and Dainty, A. R. J. (2006) The extent of team integration within construction projects. International Journal of Project Management, 24(1), pp. 13-23.

Behm, M. (2005) Linking construction fatalities to the design for construction safety concept. Safety Science, 43(8), pp. 589-611.

Bird, F. E., and Germain, G. L. (1996) Practical loss control leadership, Ga: Det Norske Veritas.

CCOHS (2008) Risk versus hazards, CCOHS.

Cheng, J., Proverbs, D. G., Oduoza, C. and Fleming, C. (2005) A conceptual model towards the measurement of construction client satisfaction. In: Khosrowshahi, F. (Ed.), 21st Annual ARCOM Conference. University of London, Association of Researchers in Construction Management.

Chicken, J. C. and Posner, T. (1998) The philosophy of risk, Thomas Telford.

Chua, D. K. H. and Goh, Y. M. (2004) Incident Causation Model for Improving Feedback of Safety Knowledge. Journal of Construction Engineering and Management, 130(4), pp. 542-551. 
Chua, D. K. H. and Goh, Y. M. (2005) Poisson model of construction incident occurrence. Journal of Construction Engineering and Management, 131(6), pp. 715-722.

Darshi De Saram, D. and Tang, S. L. (2005) Pain and suffering costs of persons in construction accidents: Hong Kong experience. Construction Management and Economics, 23(6), pp. 645658.

Duffus, J. and Worth, H. (2001) The science of chemical safety, International Union of Pure and Applied chemistry.

Egbu, C. O. (1999) Skills, knowledge and competencies for managing construction refurbishment. Construction Management and Economics, 17(1), pp. 29-43.

Elvik, R. (2006) Laws of accident causation. Accident Analysis and Prevention, 38(4), pp. 742747.

Entec UK Ltd. (2000) Construction health and safety for the new millennium. Contract Research Report 313/2000. HSE.

Eriksson, P. E. (2010) Partnering: what is it, when should it be used, and how should it be implemented? Construction Management and Economics, 28 (9), pp. 905-917.

Gibb, A. G. F. (1999) Principles in off-site fabrication, Caithness: Whittles.

Gibb, A. G. F. (2001) Standardization and pre-assembly - distinguishing myth from reality using case study research. Construction Management and Economics, 19(3), pp. 307-315.

Groeneweg, J. (1994) Controlling the controllable: The management of safety, 2nd Revised Edition, Leiden University: DSWO Press.

Haddon, W. (1980) The basic strategies for reducing damage from hazards of all kinds. Hazard prevention, September/October, pp. 8-12.

Hallowell and Gambatese (2009) Construction safety risk mitigation. Journal of Construction Engineering and Management, 135(12), pp. 1316-1323.

Haslam, R. A., Hide, S. A., Gibb, A. G. F., Gyi, D. E., Pavitt, T., Atkinson, S. and Duff, A. R. (2005) Contributing factors in construction accidents. Applied Ergonomics, 36(4), pp. 401-415.

Heinrich, H. W. (1936) Industrial accident prevention, New York: McGraw-Hill.

Henderson, J., Whittington, C., and Wright, K. (2001) Accident investigation-The drivers, methods and outcomes. HSE Contract Research Report 344/2001, HSE.

Hinze, J. (1996) The distraction theory of accident causation. In Diaz, L. M. A. and Coble, R. J. (Eds.) International Conference on implementation of safety and health on construction sites, CIB Working Commission W99: Safety and Health on Construction Sites. Balkema, Rotterdam, The Netherlands.

HSE (2009) Construction intelligence report: Analysis of construction injury and ill-health intelligence. HSE. Available online at www.hse.gov.uk/construction/pdf/conintreport.pdf. [Accessed on 7th December, 2009].

Hughes, P. and Ferrett, E. (2008) Introduction to health and safety in construction, 3rd Edition, Oxford: Elsevier Ltd.

HSL (1999) The impact of procurement and contracting practices on health and safety - A review of literature. Report: RAS/99/02. HSL.

Imriyas, K., Low, S. P., Teo, A. L., and Chan, S. L. (2008) Premium-rating model for workers' compensation insurance in construction. Journal of Construction Engineering and Management, 134(8), pp. 601-617.

Lehto and Salvendy (1991) Models of accident causation and their application: Review and reappraisal. Journal of Engineering and Technology Management, 8(2), pp. 173-205. 
Loughborough University (2006) Avoiding structural collapses in refurbishment - A decision support system. HSE Research Report 204, HSE.

Loughborough University (2009) Phase 2 Report: Health and safety in the construction industry: Underlying causes of construction fatal accidents -External research, HSE.

Loughborough University and Milan Polytechnic (2004) Health and safety in refurbishment involving demolition and structural instability. HSE Research Report 204, HSE.

Loughborough University and UMIST (2003) Causal factors in construction accidents. HSE Research Report 156, HSE.

Manu, P., Ankrah, N., Proverbs, D. and Suresh, S. (2010a) Exploring the causal influence of construction project features in accident causation. In: Barrett, P., Amaratunga, D., Haigh, R., Keraminiyage, K., Pathirage, C. (Eds.), Proceedings of CIB 2010 Congress, 10-13th May, Salford, UK.

Manu, P., Ankrah, N., Proverbs, D., and Suresh, S. (2010b) An approach for determining the extent of contribution of construction project features to accident causation. Safety Science, 48 (6), pp. 687-692.

Matthews, J. and Rowlinson, S. (1999) Partnering: incorporating safety management. Engineering, Construction and Architectural Management, 6(4), pp. 347-357.

Mayhew, C. and Quinlan, M. (1997) Subcontracting and occupational health and safety in the residential building industry. Industrial Relations Journal, 28(3), pp. 192-205.

McKay, L. J., Gibb, A. G. F., Haslam, R. and Pendlebury, M. (2002) Implications for the effect of standardization and pre-assembly on health, safety and accident causality- preliminary results. In: Greenwood, D. (Ed.) 18th Annual ARCOM Conference. University of Northumbria, Association of Researchers in Construction Management.

Mitropoulos, P., Abdelhamid, T. S., and Howell, G. A. (2005) Systems model of construction accident causation. Journal of Construction Engineering and Management, 131(7), pp. 816-825.

Perttula, P., Merjama, J., Kiurula, M. and Laitinen, H. (2003) Accidents in materials handling at construction sites. Construction Management and Economics, 21(7), pp. 729-736.

Qureshi, Z. H. (2007) A review of accident modelling approaches for complex socio-technical systems. In: 12th Australian Workshop on Safety Related Programmable Systems, Adelaide.

Reason, J. (1990) Human error, New York, Cambridge: University Press.

Shapira, A., and Lyachin, B. (2009) Identification and analysis of factors affecting safety on construction sites with tower cranes. Journal of Construction Engineering and Management, 135(1), pp. 24-33.

Strategic Forum for Construction (2002) Accelerating change: a report by the Strategic Forum for Construction, chaired by Sir John Egan, London, Rethinking Construction.

Suraji, A., Duff, A. R. and Peckitt, S. J. (2001) Development of a causal model of construction accident causation. Journal of Construction Engineering and Management, 127(4), pp. 337-344.

Szymberski, R. (1997) Construction project safety planning. TAPPI Journal, 80(11), pp. 69-74.

Wright, M., Bendig, M., Pavitt, T. and Gibb, A. (2003) The case for CDM: better safer design-a pilot study. Research Report 148, HSE. 